\title{
Permeability Experiment of Fractured Rock with Rough Surfaces under Different Stress Conditions
}

\author{
Zilong Zhou, ${ }^{1}$ Jing Zhang, ${ }^{1}$ Xin Cai $\mathbb{D}^{1},{ }^{1}$ Shanyong Wang, ${ }^{2}$ Xueming Du, ${ }^{3}$ and Haizhi Zang ${ }^{1,2}$ \\ ${ }^{1}$ School of Resources and Safety Engineering, Central South University, Changsha 410083, China \\ ${ }^{2}$ Faculty of Engineering and Built Environment, ARC Centre of Excellence for Geotechnical Science and Engineering, The University \\ of Newcastle, Callaghan 2308, Australia \\ ${ }^{3}$ College of Water Conservancy and Environmental Engineering, Zhengzhou University, Zhengzhou 450001, China
}

Correspondence should be addressed to Xin Cai; xincai@csu.edu.cn

Received 24 February 2020; Accepted 20 May 2020; Published 1 June 2020

Academic Editor: Qian Yin

Copyright @ 2020 Zilong Zhou et al. This is an open access article distributed under the Creative Commons Attribution License, which permits unrestricted use, distribution, and reproduction in any medium, provided the original work is properly cited.

\begin{abstract}
To investigate the permeability changes and the mechanisms of fractured rock under dynamic and static stresses produced by earthquakes, permeability experiments on fractured rock with rough surfaces under axial dynamic and static stresses were conducted on the MTS815 Rock Mechanics Testing System. Surface asperity was investigated by scanning the specimen surfaces before and after testing. The results show that the roughness of fracture surface has a great influence on the permeability when the axial displacement is not enough to cause the fracture rock to slip. Moreover, the rougher fracture surface leads to severer surface damage as indicated by the more gouge productions. The accumulation of gouge materials on larger roughness fracture surfaces causes a slow drop in permeability. The fracture surfaces experience larger degradations, but it has small weights of gouge materials on fracture surface after testing under axial dynamic stress. The reason is that the gouge material transport and mobilization tend to occur in process of dynamic loading. Therefore, the permeability drops of axial dynamic stress are larger than those of axial static stress.
\end{abstract}

\section{Introduction}

Permeability of rock fracture is governing fluid filtration rates and particle mobilization [1] and the main parameter of the safety properties of fractured rock mass [2]. Permeability varies with the changes of roughness [3] and the production of gouge materials [4], when the deformation of fracture occurs under stress [5-7]. It is known that fractured rock is often subjected to significant dynamic and static stresses produced by earthquakes [8-19]. Therefore, the permeability changes and the mechanisms of fractured rock under dynamic stress and static stress are very important to predict seismic activity.

Permeability changes caused by various mechanisms, including the unclogging and clogging of fractures, variations in the fracture aperture, and the particle mobilization, under static stress have been observed in both the field and the laboratory. Some researchers found the permeability of fracture decreases with the increase effective static stress [20-26]. Vogler et al. found that gouge material production may have caused clogging of the main fluid flow channels, resulting in reductions of permeability by up to one order of magnitude [4]. Zhao et al. investigated that the permeability decreases with the fracture apertures decrease in effective stress, and the effect of fracture roughness on the permeability is related to the magnitude of effective stress [27]. Wu et al. measured the roughness and the permeability drop with effective stress. The permeability of natural fracture only partially recovers after effective stress returns to initial value and decreases due to produced gouge blocking fluid flow pathways [3].

Some studies suggested that dynamic stress can lead to the severe fatigue damage or failure of rock even when the stress level is significantly lower than the static strength [28-31] and can change permeability. Brodsky [32] and Elkhoury et al. [33] found that distant earthquakes may even increase the permeability in faults by unclogging of fractures in the field. Xue et al. [34] and Shi and Wang [35] studied that after a large earthquake, the fault zone permeability transiently increases because of earthquakes generating fractures 
in a damage fault in Wenchuan earthquake. Faoro et al. [36] showed transient increase in the effective permeability of the rock mass caused by dilates in the fracture aperture with fluid pressure at laboratory scale. Candela et al. [37] conducted that transient fluid pressure in fractured rock commonly involves permeability increases and has been attributed to mobilization of fine particles in laboratory experiments. In addition, a few studies have detected that earthquakes could decrease permeability [38-40]. For example, Shi et al. found the earthquake-induced permeability decrease in the fault zone reduced the recharge from deep hot water [39]. Given the azimuthal distribution of distant earthquakes, the observed permeability decrease could be attributed to the seismic wave-induced clogging of fractures that compose the flow paths in the shallow crust [40]. Shmonov et al. [8] applied oscillatory stresses to unfractured cores at high confining pressures and temperatures and found that permeability is more likely to increase. Liu and Manga [41] conducted similar experiments on already fractured sandstone cores saturated with deionized water and showed that the permeability in fractured sandstone can potentially decrease under the effect of dynamic stresses. Various mechanisms have been tried to explain the increases in permeability caused by dynamic stresses induced by the passage of seismic waves [40]. However, these mechanisms are poorly understood, and thus, it is difficult to predict permeability increase or decrease under dynamic stress and static stress.

In this study, the experiments of effect of axial dynamic stress and static stress on permeability were conducted on the MTS815 Rock Mechanics Testing System. The fracture roughness change was investigated by scanning the sample surfaces before and after testing. The permeability characteristics under axial dynamic stress and axial static stress were analyzed considering the asperity degradations and gouge materials of fracture surfaces. This provides the information on the impact of production, transport, and flow mobilization of gouge material on permeability changes under dynamic stress.

\section{Test Preparation}

2.1. Sample Preparation. The rock material used in this study is a fine-grained sandstone collected from the northwest of Kunming, Yunnan province of China. A series of preliminary tests have been conducted on standard rock samples to determine the crucial mechanical parameters of the sandstone, such as Young's modulus (34 GPa), Poisson's ratio (0.3), and uniaxial compressive strength $(86 \mathrm{MPa})$.

All samples were extracted from one single sandstone slab to minimize the variations in properties [42]. Then, samples were manufactured into cylindrical geometry with $50 \mathrm{~mm}$ in diameter and $100 \mathrm{~mm}$ in length. Each sample was split at a 30-degree angle with respect to the axis to form a fracture surface, as shown in Figure 1(a). Subsequently, one borehole with $3 \mathrm{~mm}$ diameter was drilled parallel to the axial direction, at the corner of each half to facilitate fluid flow from core holders into the fracture (Figure 1(b)). After that, samples were saturated by soaking in water for more than 12 hours.
2.2. Surface Roughness Measurements. Fracture surface characteristics were scanned with an optical three-dimensional scanner manufactured by GOM (ATOS III TRIPLE SCAN). The ATOS Core sensor projects fringe patterns on the object surface, which are recorded by two cameras. The patterns form a phase shift that is based on a sinusoidal intensity distribution which enables one to calculate the three-dimensional (3D) surfaces. The photogrammetry scanner is calibrated with two tests. The diameter and shape of a sphere and the distance between two spheres that are mounted on a plate are measured with the photogrammetry scanner to derive calibration errors and accuracy. All equipment used for calibration are specifically developed by the company GOM, which manufactures the scanner. The overall scanning accuracy is less than $0.01 \mathrm{~mm}$ within the scanning range of $100 \times 75 \mathrm{~mm}^{2}$, and length deviation errors are between 0.009 and $0.027 \mathrm{~mm}$. The measurement resolution is $3692 \times 2472$ pixel with optimized calibration deviations of $0.014 \pm 0.001$ pixels. In addition, the tensile fractures were prepared carefully with a high degree of fracture matching; therefore, the joint matching coefficient of the fractures is close to 1.0. So we only use one fracture surface of each sample in the scanning contour before and after testing. After the 3D scanning, the digitized data were exported in xyz file format to estimate the fracture roughness. The surface roughness parameter, $Z_{2}$, the root mean square of the slope of a $2 \mathrm{D}$ profile, is widely used to correlate with the JRC value [43-46]. For a $2 \mathrm{D}$ profile, $Z_{2}$ is given by

$$
\begin{aligned}
Z_{2} & =\left[\frac{1}{(n-1)(\Delta x)^{2}} \sum_{i=1}^{i=n-1}\left(Z_{i+1}-Z_{i}\right)^{2}\right]^{0.5}, \\
\mathrm{JRC} & =61.79 Z_{2}-3.47,
\end{aligned}
$$

where $Z_{2}$ is the root mean square of the slope of a given 2D profile, $n$ is the number of data points along the $2 \mathrm{D}$ profile, $\Delta x$ is the interval between the data points, $Z_{i}$ is the value of the asperity height at point $I$, and JRC is the joint roughness coefficient.

As in many previous studies, an interval of $0.5 \mathrm{~mm}$ for sampling points was selected to estimate the roughness [43-46]. JRC of each profile on the fracture surface was calculated using equation (2), and the mean value of JRC was calculated to characterize the roughness of the fracture surface as listed in Table 1 . They are a set of 10 typical roughness profiles as shown in Figure 2. The mean JRC values of samples Ss-1 and Sd-1 belong to the roughness profile type 4, that of samples Ss-2 and Sd-2 is the roughness profile type 5, and that of samples Ss-3 and Sd-3 is of the roughness profile type 10. The same process was repeated for the damaged surfaces after testing to analyze the surface changes that occurred during the experiments and compare these to the changes in permeability during the experiment.

2.3. Experimental Setup and Procedure. All experiments were conducted on a servo-controlled Rock Mechanics Testing System (MTS815) housed at the Advanced Research Center 


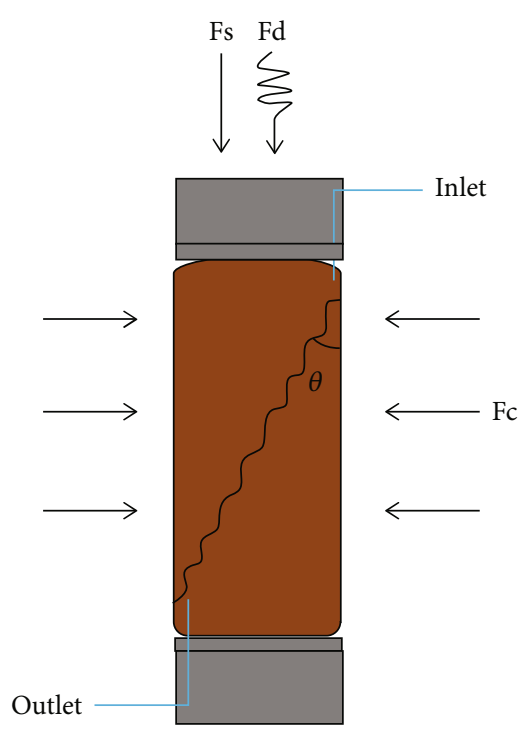

(a)

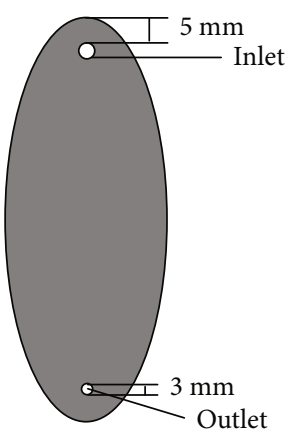

(b)

FIGURE 1: (a) Sketch of fractured rock sample and (b) a rough fracture with boreholes for fluid flow.

in Central South University. The system consists of five main units: a triaxial cell, a loading unit, a water supply unit, a deformation and pressure monitoring unit, and a dataacquisition unit. The maximum loading capacity of the system is up to $4600 \mathrm{kN}$. The maximum confining pressure and pore water pressure are $140 \mathrm{MPa}$. The axial deformation of the sample is measured by a pair of linear variable displacement transducers (LVDTs). The system is configured with a transient pulse apparatus for the permeability test of cylinder rock specimen. The permeability was measured with a pressure pulse-decay technique testing method as shown in Figure 3.

Two suites of permeability experiments on fractured rock were conducted. In the "axial dynamic test" suite of experiments, three groups (Sd-1, Sd-2, and Sd-3) of tests were designed. The experimental procedure includes the following steps:

(1) Each sample was wrapped in a Teflon tape to avoid the slippage in the opening fracture when exerting the confining stress and preaxial static stress. Then, the sample was circumferentially sealed in a thermo-shrinking plastic membrane to separate the sample from the confining fluid. After that, the rock sample was placed at the triaxial cell filled with hydraulic oil

(2) The confining stress $\left(\sigma_{3}\right)$ and static axial stress $\left(\sigma_{s}\right)$ were successively increased to the designed levels at a constant loading rate of $0.1 \mathrm{MPa} / \mathrm{s}$. They were, respectively, set at $5 \mathrm{MPa}$ and $10 \mathrm{MPa}$ in all tests and kept constant during the whole test

(3) Five minutes later, the sample and the loading system became stable. The successive axial sine wave was applied to the top of the sample by a rigid loading bar. The actual axial stress is the superposition of the static prestress and the cyclic stress as

$$
\sigma_{\mathrm{sd}}=\sigma_{\mathrm{s}}+\sigma_{\mathrm{d}} \sin (2 \pi f t)
$$

where $\sigma_{\mathrm{sd}}$ is the superimposed axial stress, $\sigma_{\mathrm{s}}$ is static axial stress, $\sigma_{\mathrm{d}}$ is the amplitude of dynamic axial stress, $f$ is the frequency, and $t$ is the time. Preliminary compression tests on the fracture rock sample suggested that the critical axial stress for the slippage of the sample under the confining pressure of $5 \mathrm{MPa}$ is $15 \mathrm{MPa}$. Hence, the superimposed axial stress should be limited below the critical stress. In this study, the axial stress was independent variables as listed in Table 1. Three groups of tests were designed according to the amplitude of dynamic stress, i.e., $0.25,1.25,2.5$, 3.75 , and $5 \mathrm{MPa}$. The loading paths with the frequency of $1 \mathrm{~Hz}$ were plotted in Figure 4

(4) After the sample was subjected to 100 cycles of dynamic disturbance, the cyclic loading stopped, and then, the confining pressure and static axial stress were still maintained at $5 \mathrm{MPa}$ and $10 \mathrm{MPa}$. Then, an initial water pressure was applied to both the upstream and downstream reservoirs, at a loading rate of $0.2 \mathrm{MPa} / \mathrm{min}$. Next, the water pressure in the upstream reservoir suddenly increased to form a differential pressure (i.e., an initial pulse pressure) which makes the water flow from the top to the bottom through the fracture, as shown in Figure 3. The time pulse pressure $(\Delta P)$ decreased over time until equilibrium was attained. It was automatically monitored and recorded by two pressure gages in the water 
TABLE 1: Test parameter for stress conditions.

\begin{tabular}{|c|c|c|c|c|c|c|c|c|}
\hline Sample & Mean JCR value & Roughness profile type & Subset & $\sigma_{3}(\mathrm{MPa})$ & Fs $(\mathrm{MPa})$ & $\mathrm{Fd}(\mathrm{MPa})$ & Cycles & $f(\mathrm{~Hz})$ \\
\hline & & & 1 & & & 0.25 & & \\
\hline & & & 2 & & & 1.25 & & \\
\hline \multirow[t]{5}{*}{ Sd-1 } & 6.26 & 4 & 3 & 5 & 10 & 2.5 & 100 & 1 \\
\hline & & & 4 & & & 3.75 & & \\
\hline & & & 5 & & & 5 & & \\
\hline & & & 1 & & & 0.25 & & \\
\hline & & & 2 & & & 1.25 & & \\
\hline \multirow[t]{5}{*}{ Sd-2 } & 9.256 & 5 & 3 & 5 & 10 & 2.5 & 100 & 1 \\
\hline & & & 4 & & & 3.75 & & \\
\hline & & & 5 & & & 5 & & \\
\hline & & & 1 & & & 0.25 & & \\
\hline & & & 2 & & & 1.25 & & \\
\hline \multirow[t]{5}{*}{ Sd-3 } & 19.35 & 10 & 3 & 5 & 10 & 2.5 & 100 & 1 \\
\hline & & & 4 & & & 3.75 & & \\
\hline & & & 5 & & & 5 & & \\
\hline & & & 1 & & 5 & & & \\
\hline & & & 2 & & 7.5 & & & \\
\hline \multirow[t]{5}{*}{ Ss-1 } & 7.025 & 4 & 3 & 5 & 10 & 0 & 100 & 0 \\
\hline & & & 4 & & 12.5 & & & \\
\hline & & & 5 & & 15 & & & \\
\hline & & & 1 & & 5 & & & \\
\hline & & & 2 & & 7.5 & & & \\
\hline \multirow[t]{5}{*}{ Ss-2 } & 9.135 & 5 & 3 & 5 & 10 & 0 & 100 & \\
\hline & & & 4 & & 12.5 & & & \\
\hline & & & 5 & & 15 & & & \\
\hline & & & 1 & & 5 & & & \\
\hline & & & 2 & & 7.5 & & & \\
\hline \multirow[t]{3}{*}{ Ss-3 } & 20 & 10 & 3 & 5 & 10 & 0 & 100 & 0 \\
\hline & & & 4 & & 12.5 & & & \\
\hline & & & 5 & & 15 & & & \\
\hline
\end{tabular}

tank. Accordingly, the permeability of the fractured sample can be obtained (see Section 2.4)

In the "axial static test" suite of experiments, three groups (Ss-1, Ss-2, and Ss-3) of tests were also designed. In each experiment, the axial stress was raised from 5 to $15 \mathrm{MPa}$ in step of $2.5 \mathrm{MPa}$, and the confining pressure was kept at $5 \mathrm{MPa}$ as listed in Table 1 . The permeability of fractured rock was measured at each axial loading.

2.4. Permeability Measurements. Rock permeability can be measured using a steady state method, in which the flow rate of a fluid through a sample is measured for a known hydraulic pressure gradient. When permeability is low, however, a long time may be required to establish a steady state. This method is based on the analysis of the decay of a small-step change of the pressure imposed at one end of a specimen.
In this study, the differential pressure along the fault plane after achieving a pressure step is measured; then, the permeability is calculated as [3]

$$
k=\frac{c L \mu}{A_{2} P_{\mathrm{m}}\left(1 / V_{1}+1 / V_{2}\right)},
$$

where $P_{\mathrm{m}}$ is the average value of $P_{V_{1}}$ and $P_{V_{2}}, P_{V_{1}}$ and $P_{V_{2}}$ are the upstream and downstream pressure, $\mu$ is the water viscosity $\left(1.01 \times 10^{-3} \mathrm{~Pa} \cdot \mathrm{s}\right), L$ is the distance between the two drilled boreholes along the fault plane, $A_{2}$ is the cross-sectional area of the fracture, $V_{1}$ and $V_{2}$ are the upstream and downstream reservoir volumes $\left(V_{1}=V_{2}=3.32 \times 10^{-7} \mathrm{~m}^{3}\right.$ for the MTS experimental setup as shown in Figure 3), and $c$ is the rate of the variation rate of the time pulse pressure with time, which can be determined according to the evolution of the time pulse pressure $(\Delta P)$. Brace et al. [47] and Jang et al. 


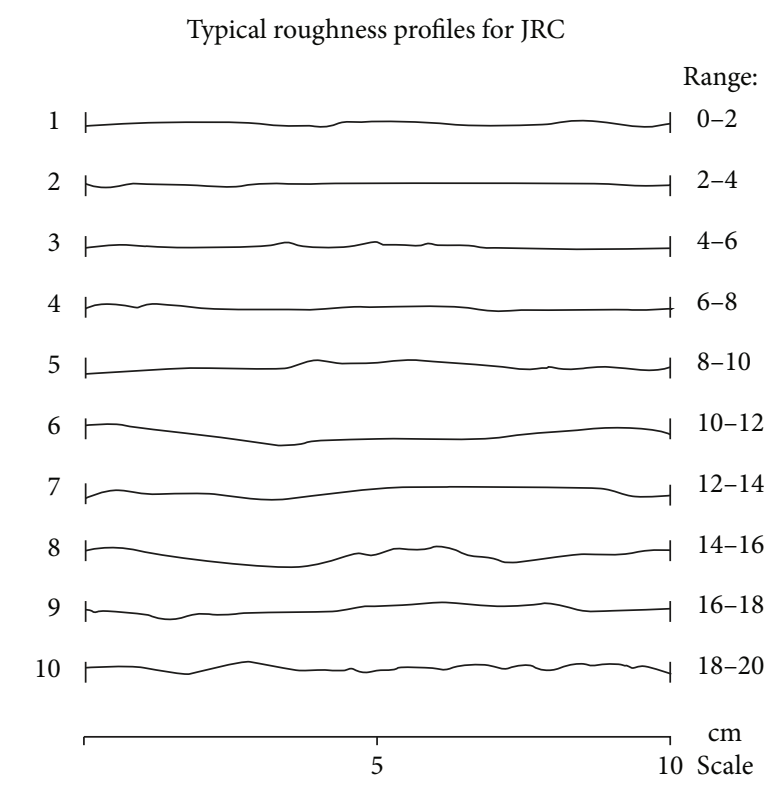

FIGURE 2: 10 typical roughness profiles showing the range of JRC values [44].

[48] suggested that the time pulse pressure exponentially attenuates with time as

$$
\Delta P(t)=P_{0}\left(e^{-c t}\right)+c_{0}
$$

where $P_{0}$ is the initial pulse pressure at time $t=0$ and $c_{0}$ is a fitting constant. Figure 5 presents the variation of the time pulse pressure versus time. It can be seen that the decay model of the time pulse pressure (equation (5)) matches the trend of test data well. Clearly, the coefficient $c$ is 0.0021 .

\section{Results and Discussions}

Our data shows that (1) the permeability changes are negatively correlated with the axial stress, (2) the permeability changes are affected by the roughness of fracture surfaces, and (3) the fractures of dynamic stress have slightly higher permeability drops compared to the fracture of static stress. We consider three influencing factors for transient permeability changes: (i) initial mean value of JRC, (ii) asperity degradation and gouge materials, and (iii) particle mobilization.

3.1. Permeability Changes. Figure 6 depicts the permeability evolution and axial displacements under axial dynamic stress. Figure 6 shows the permeability variation of Sd-1 and Sd-2 decreases at similar rates, while the axial displacements of Sd-1 and Sd-2 increase at similar rates. The permeability of Sd-3 drops slower and the axial displacement rises faster. Overall, three groups show an apparent reduction in the permeability with the rising amplitude under axial dynamic stress, an enhancement in axial displacement with that. This phenomenon does not match those observed in earlier studies that the decrease of permeability is sharp with increasing slip displacement $[3,4,49,50]$. Figure 7 indicates the changes of permeability before and after testing under axial dynamic stress and axial static stress. It is found that the permeability of Sd-1 and Sd-2 drops with $35 \%$ and $37 \%$ decline rate, and that of Sd-3 goes down $44 \%$ as presented in Figure 7. However, the mean JRC values of samples Sd-1 and Sd-2 belonging to the roughness profile types 4 and 5 are lower than those of sample Sd-3 in Table 1.

The similar phenomenon occurs under static stress. The changes of permeability and axial displacements of Ss-1 and Ss-2 are similar, while the permeability of Ss-3 decreases slowly and the axial displacements increase largely as presented in Figure 8. The roughness of fracture surfaces of Ss1 and Ss- 2 is smaller than that of Ss- 3 under axial static stress (Table 1). The permeability values of Ss-1, Ss-2, and Ss-3, respectively, decrease with the decline rates $13 \%, 14 \%$, and $20 \%$ in Figure 9. Figures 7 and 8 show that all the axial displacements are less than $1 \mathrm{~mm}$ and the fracture rocks are not damaged in two suites of permeability experiments. This indicates that when the axial displacement is not enough to cause the fracture rock to slip under the same stress conditions, the roughness of fracture surface has a great influence on the permeability.

3.2. Topographic Changes of Fracture Surfaces. Due to the large axial forces, significant surface deformation is expected in the fracture plane of the sample. For detailed analysis, the photogrammetric surface scans of the fracture sample and the mean values of JRC are generated before and after two suites of permeability experiments as shown in Figures 1013. Photogrammetric scans produced profiles of the surfaces, which are oriented according to a best-fit plane in the $x-y$ coordinates. For visualization and comparison, an asperity height of $0 \mathrm{~mm}$ is assigned to the lowest point of the surface for Figures 10 and 12. Note that the same color scales are used. The changes of the mean values of JRC before and after testing under dynamic stress and that under static stress are, respectively, presented in Figure 13.

Figures 10 and 11 show the surface scans and the changes of the mean values of JRC of samples Sd-1, Sd-2, and Sd-3 before and after testing under axial dynamic stress. Comparing the fracture surfaces before and after testing, the maximum surface reliefs of Sd-1, Sd-2, and Sd-3 are, respectively, from $3.635 \mathrm{~mm}$ to $3.406 \mathrm{~mm}, 8.897 \mathrm{~mm}$ to $6.625 \mathrm{~mm}$, and $5.448 \mathrm{~mm}$ to $4.835 \mathrm{~mm}$ in asperity height (Figure 10). Figure 11 indicates that the mean values of JRC of Sd-1 and Sd-2 are, respectively, from 6.26 to 3.45 and from 9.26 to 4.01 with the reductions of 2.81 and 5.25 , while the mean values of JRC of Sd-3 drop from 19.35 to 6.42 with a higher reduction of 12.93. Therefore, the larger fracture roughness of Sd-3 is more decreased. This means that fracture surfaces with a high degree of relief and a large mean value of JRC variability experience more degradation during testing.

Under axial static stress, the initial maximum surface reliefs of Ss-1, Ss-2, and Ss-3 are $4.413 \mathrm{~mm}, 9.688 \mathrm{~mm}$, and $5.443 \mathrm{~mm}$ and the initial mean values of JRC of Ss-1, Ss-2, and Ss-3 are 7.03, 9.14, and 20 as shown in Figures 12 and 13. After testing, the mean values of JRC are 4.75, 5.67, and 13.15. This means that the JRC degradations of 2.28, 3.47 , and 6.85 are induced on the fracture surfaces under static stress. 




FIgURE 3: Schematic of transient permeability system.

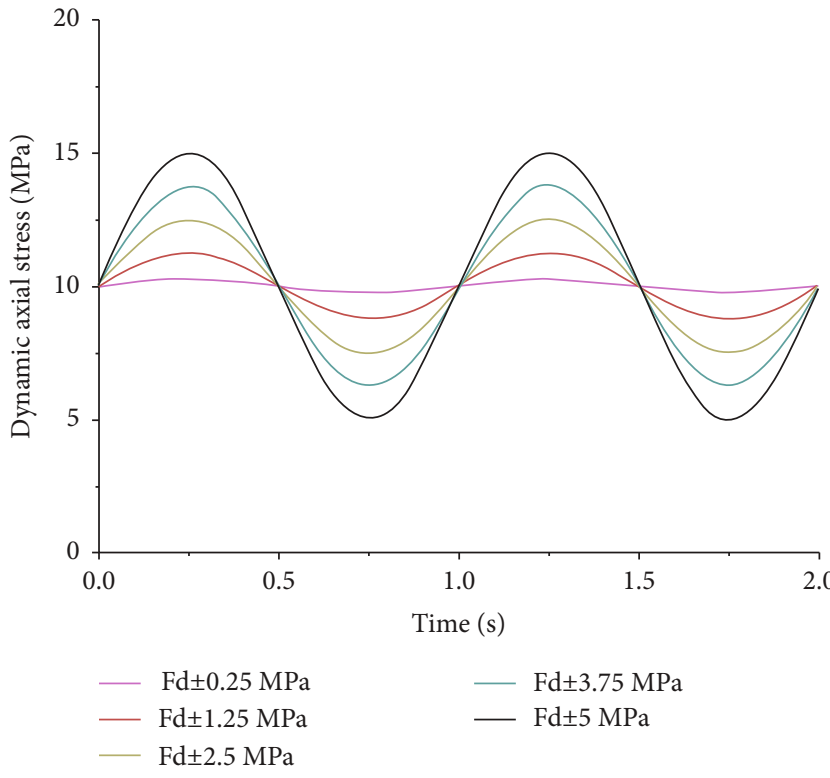

FIgURE 4: Schematic of loading paths.

3.3. Analysis of Gouge Material. Due to the experimental setup, the gouge material was not collected at the outflow end of the experiment, but that left on the fracture surface after testing was collected. The gouge material was then brushed off the surface and weighed. The weight of gouge material collected after testing is shown in Figures 14 and 15. The weights of gouge material on fracture surface of samples Sd-1, Sd-2, and Sd-3 under dynamic stress are $1.20 \mathrm{~g}$, $1.23 \mathrm{~g}$, and $1.44 \mathrm{~g}$, while those on fracture surface of samples Ss-1, Ss-2, and Ss-3 under static stress are $2.07 \mathrm{~g}, 2.11 \mathrm{~g}$, and $2.24 \mathrm{~g}$.

The mean value drop of JRC and the weight of the generated gouge materials under dynamic stress were compared as shown in Figure 14. The initial mean value of JRC of Sd-1 is smaller than that of Sd-2, and the initial mean value of JRC of Sd-1and Sd-2 is lower than that of Sd-3 (Table 1), while the drop of mean value of JRC and the weights of fracture gouge produced by Sd-1 and Sd-2 are lower than those of Sd-3 during dynamic loading.

The same phenomenon occurs under static stress in Figure 15. The initial mean value of JRC of Ss-1 and Ss-2 is smaller than that of Ss-3 under axial static stress (Table 1). The drop of mean value of JRC and the weights of fracture gouge produced by Ss-1 and Ss-3 are lower than those of Ss-2 during static loading. This means that the larger mean value of JRC of fracture surface leads to larger surface damage as indicated by the more gouge productions. This observed gouge material production could potentially cause the hysteretic behavior by subsequently clogging flow paths, thus 


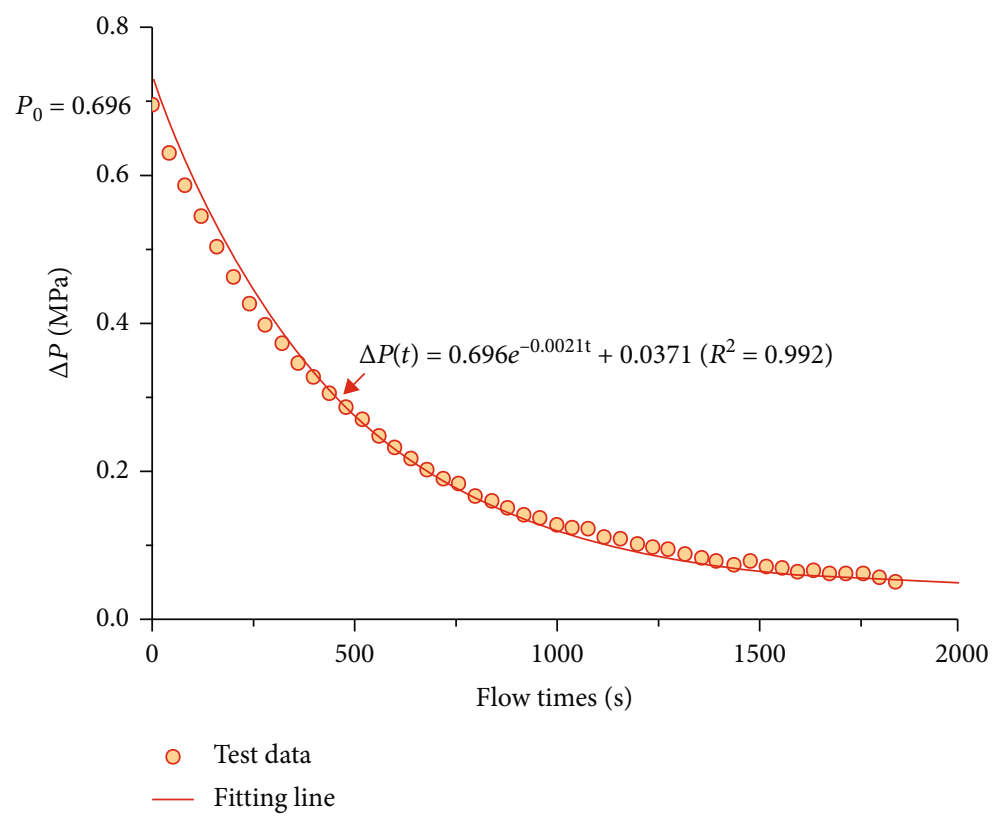

FIgURE 5: A representative differential pressure versus flow time curve.

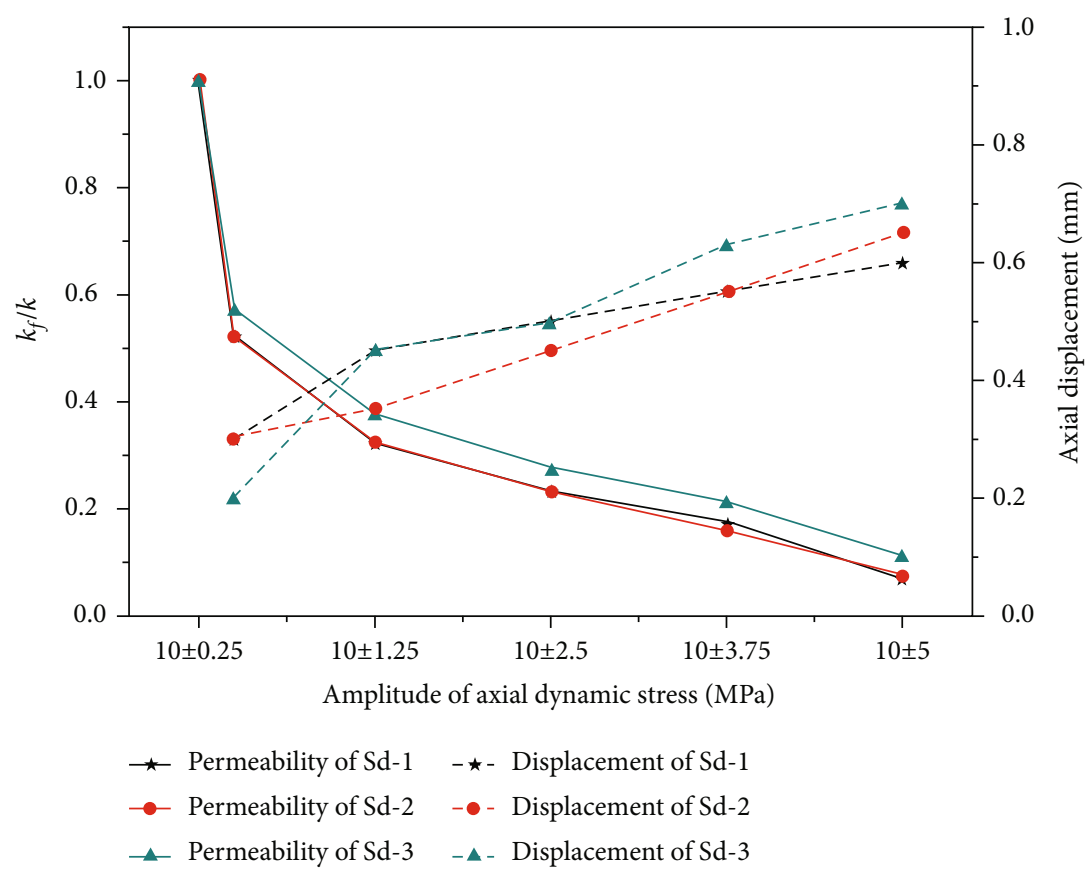

FIGURE 6: Permeability evolution and axial displacement of Sd-1, Sd-2, and Sd-3 under different amplitudes of axial stress of 10 MPa.

lowering the fracture permeability and bringing about the irregular permeability values [4]. This helps to explain that the permeability of Sd-2 drops slower than that of Sd-1 and Sd-2 under dynamic stress (Figure 6). The changes of permeability of Ss-1 and Ss-2 are similar, while the permeability of Ss-3 decreases slowly under static stress (Figure 8). Generally, under the same stress conditions, the accumulation of gouge materials on larger roughness fracture surfaces causes slower drops of permeability.
3.4. Comparing Dynamic Stress and Static Stress. Comparing the permeability changes before and after testing under dynamic and static stresses, the permeability drop, the mean value drop of JRC, and the weight of gouge material are indicated in Figure 16. Under similar roughness profile type for JRC, the permeability drops of fracture surfaces of Sd-1, Sd2 , and Sd-3 more than 35\% under axial dynamic stress are larger than the drops of permeability less than $20 \%$ under axial static stress. The mean value drop of JRC of Sd-1, Sd- 


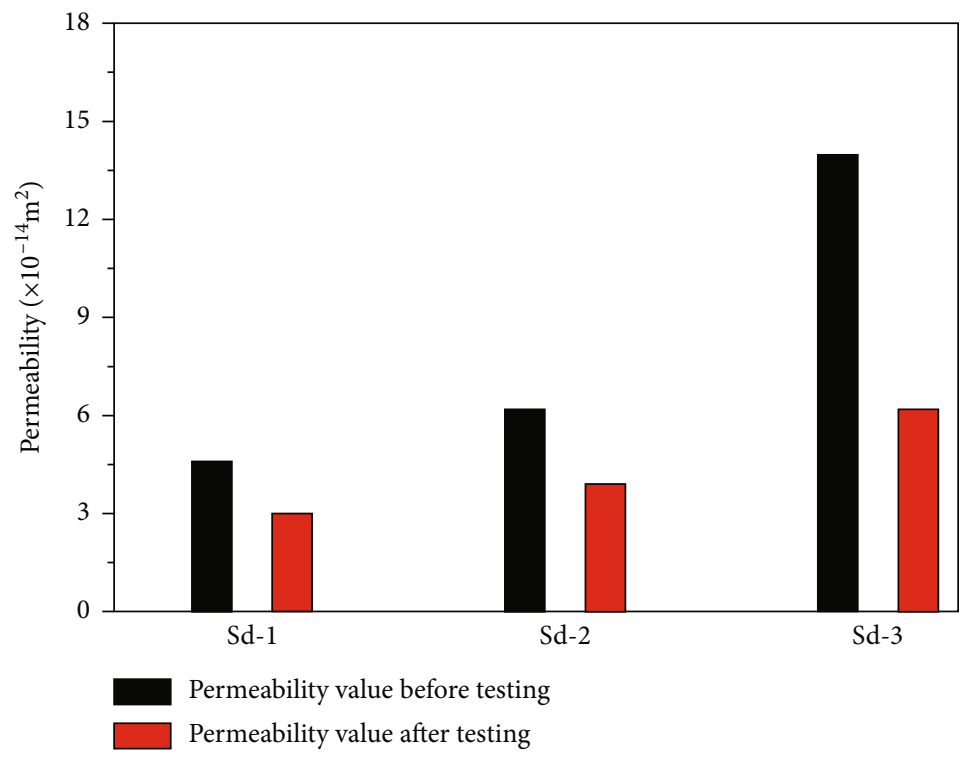

Figure 7: Permeability changes before and after testing under axial dynamic stress.

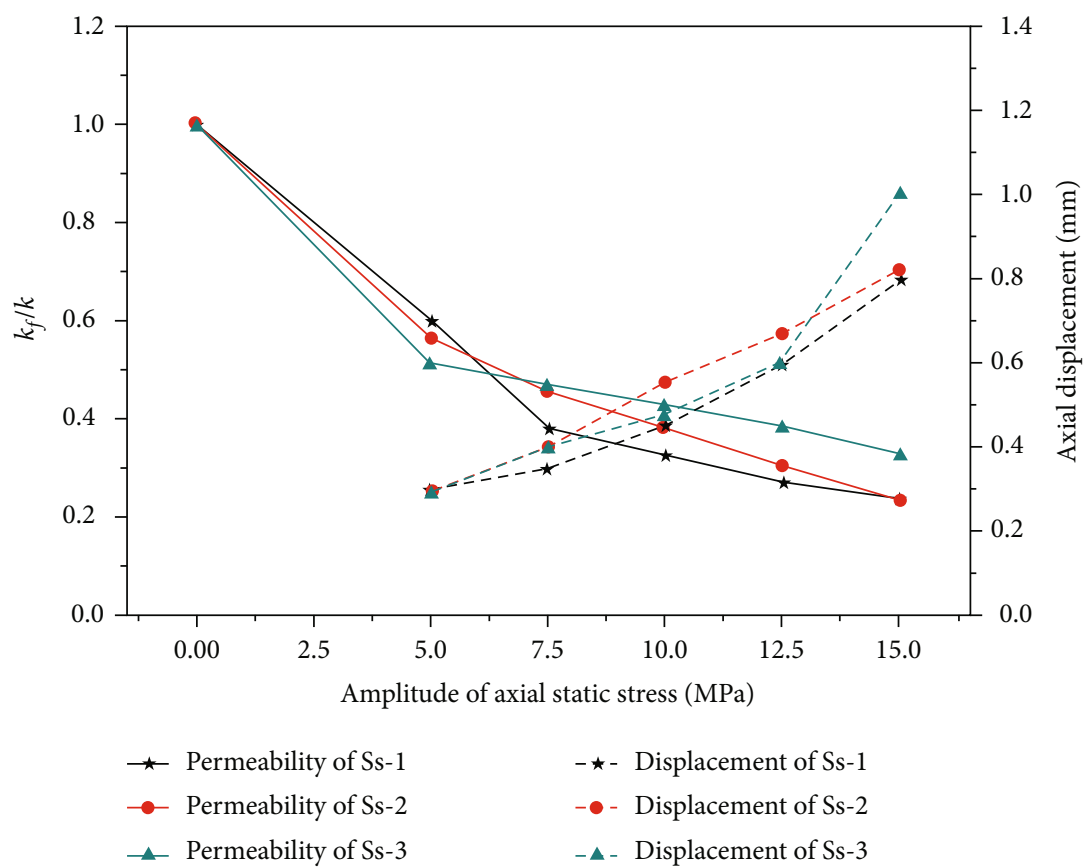

FIGURE 8: Permeability evolution and axial displacement of Ss-1, Ss-2, and Ss-3 under axial static stress.

2 , and Sd-3 is larger than that of fracture surfaces of Ss-1, Ss2 , and Ss-3. This suggests that the permeability drops of fracture surfaces under dynamic stress are greater than those under static stress, and the asperity degradations under dynamic stress are larger than those under static stress. However, the weights of gouge materials on fracture surface after testing under axial dynamic stress are smaller than those under axial static stress, which is different from more gouge materials with larger asperity degradations. Overall, under the similar rough surface, the permeability decreases of fracture surfaces are easily caused by dynamic stress through larger asperity degradations. But fewer gouge materials remain in fracture surfaces under dynamic stress conditions.

These observed responses can be summarized with a proposed conceptual model that considers permeability evolution modes of gouge material transport and flow mobilization, as shown in Figure 17. Figure 17(a) indicates that the gouge materials are more likely to stick to the fracture surface under static stress. When the forces increase, the compacted gouge materials will close the aperture, thus slowing down the rate of permeability reduction of the rock fracture (Figure 17(c)). However, the gouge materials migrate 




FIGURE 9: Permeability changes before and after testing under axial state stress.

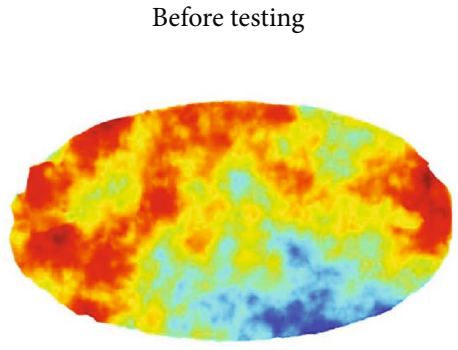

(a)

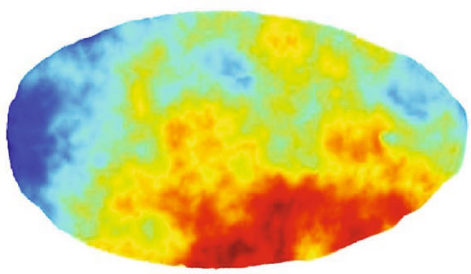

(a)

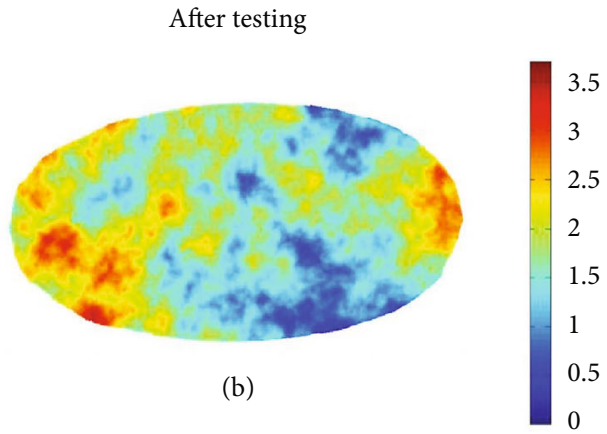

Sd-1



Sd-2

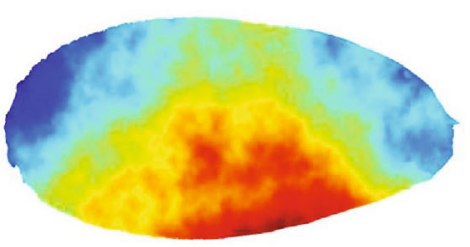

(a)



Sd-3

Figure 10: $(a, b)$ Surface scans of samples Sd-1, Sd-2, and Sd-3 before and after testing under dynamic stress. 


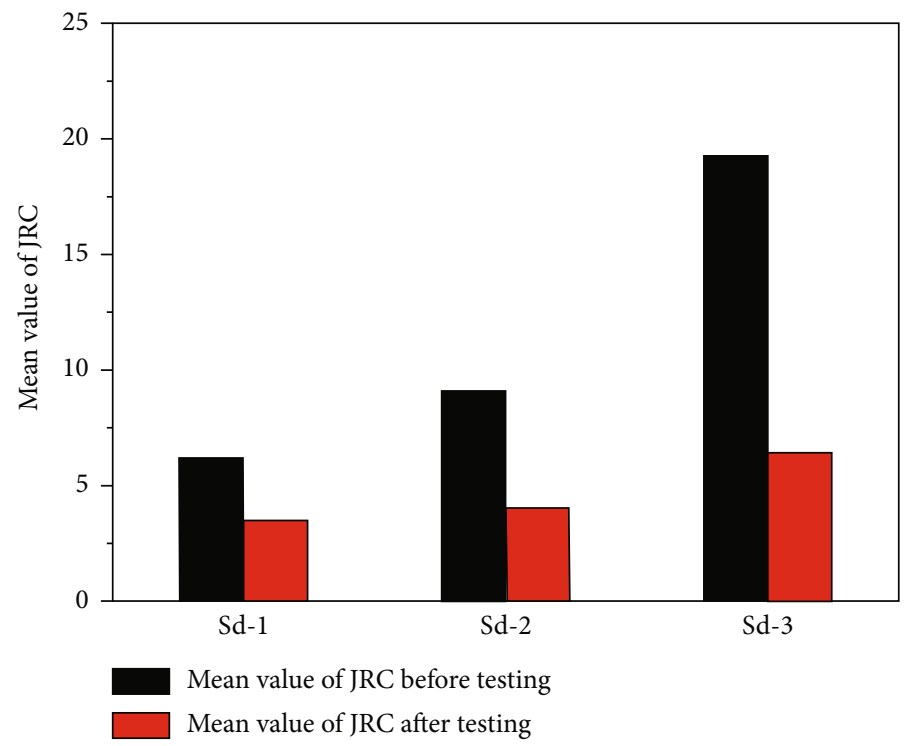

Figure 11: Mean value changes of JRC of samples Sd-1, Sd-2, and Sd-3 before and after testing under dynamic stress.

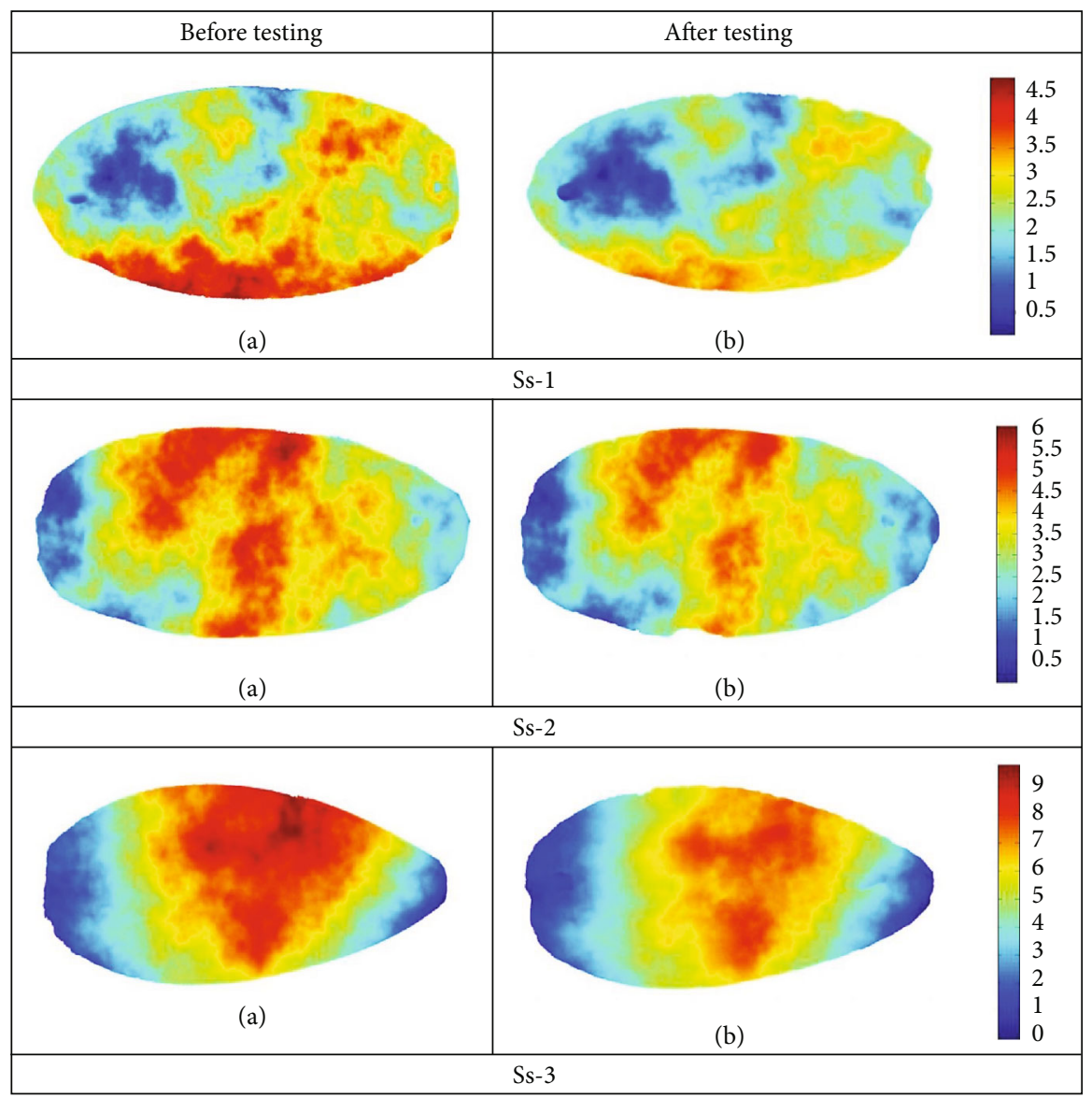

FIgURE 12: (a, b) Surface scans of samples Ss-1, Ss-2, and Ss-3 before and after testing under static stress.

gradually between fracture asperities (or the pore throats) under dynamic stress as described in Figure 17(b). During the amplitude of dynamic stress increasing, the gouge materials initially plugged between fracture asperities (or in the pore throats) are flushed, producing the permeability drop enhancement under dynamic stress than static stress observed in our experiments (Figure 17(d)). Generally, when the rough fracture surfaces are crushed under more intensive 


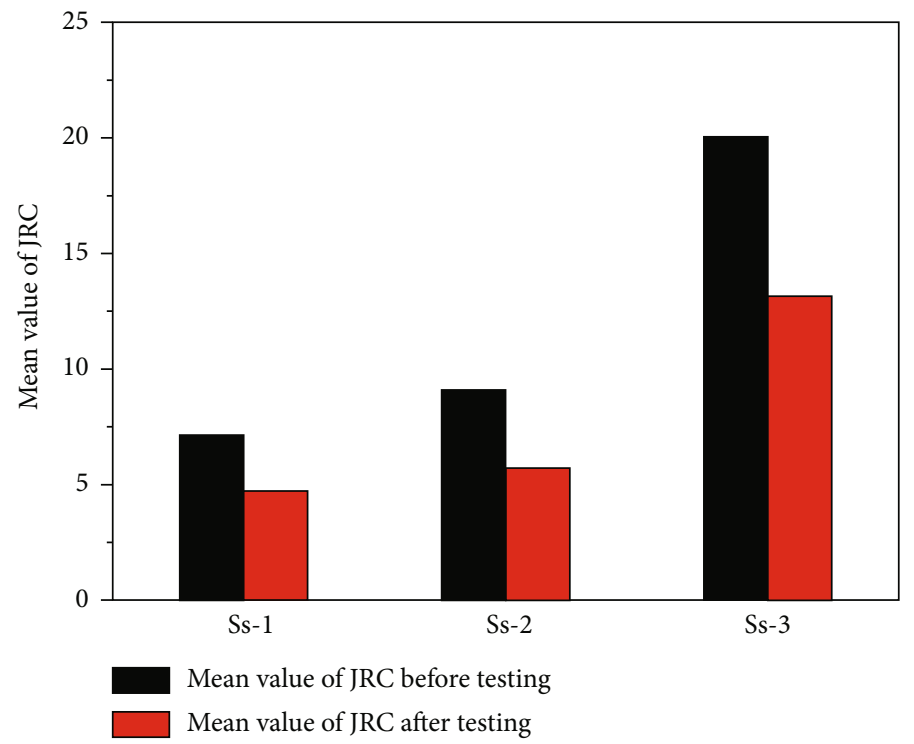

Figure 13: Mean value changes of JRC of samples Ss-1, Ss-2, and Ss-3 before and after testing under static stress.

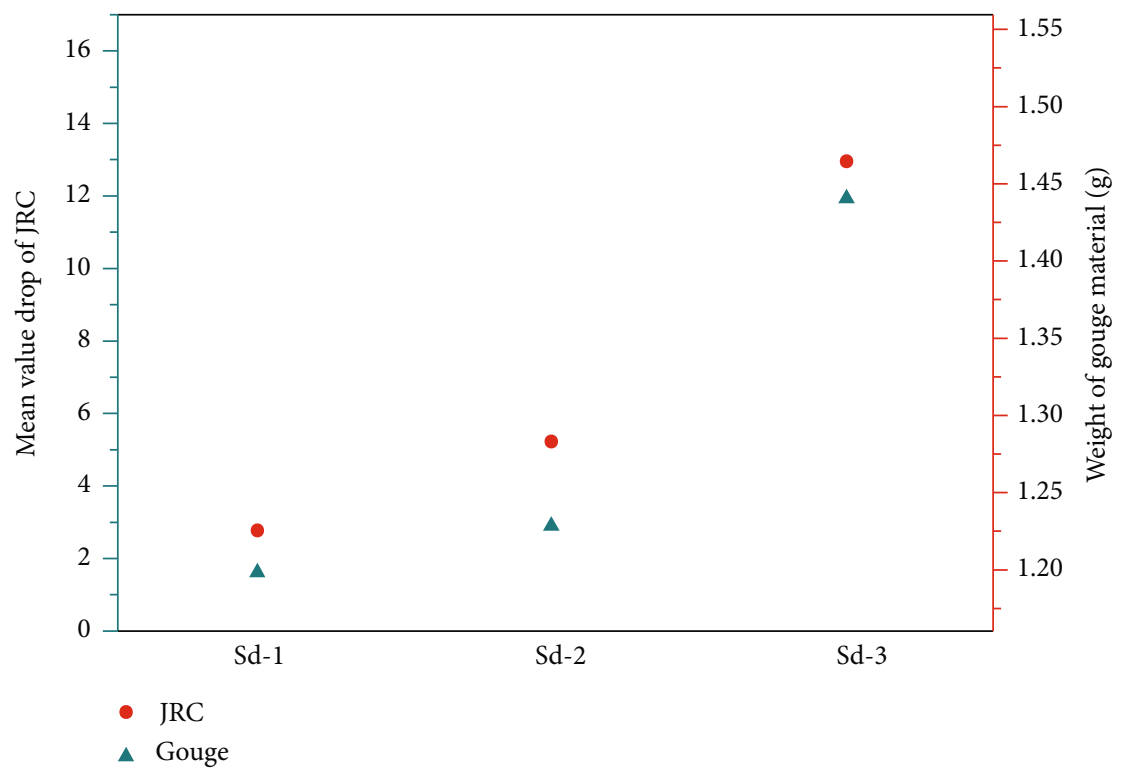

FIGURE 14: Mean value drop of JRC and weights of gouge material after testing under dynamic stress.

multiple dynamic impacts, the transport of gouge materials and the flow mobilization tend to occur during dynamic stress, causing the permeability drops of axial dynamic stress to be larger than those of axial static stress.

\section{Conclusions}

The permeability changes of nature rock fracture were investigated before and after testing under axial dynamic stress and static stress, so as to simulate the mechanisms of permeability changes of preexisting fractures via dynamic stress in fracture rock engineering. Six series of experiments under different amplitudes of cyclic axial forces and different axial static forces were conducted; the influence of surface rough- ness was investigated by scanning the specimen surfaces before and after testing; and by which, gouge material transport and flow mobilization of rock fracture were analyzed. The main findings of this paper can be summarized as follows:

(1) The axial displacements of Sd-1 and Sd-2 are lower than those of Sd-3 with dynamic stress, but the permeability of Sd-1 and Sd-2 is larger than that of Sd3 . In fact, the initial maximum and the mean value of JRC of fracture surfaces of Sd-1 and Sd-2 are smaller than those of Sd-3. This indicates that the roughness of fracture surface has a great influence on the permeability when the axial displacement is not enough to cause the fracture rock to slip 


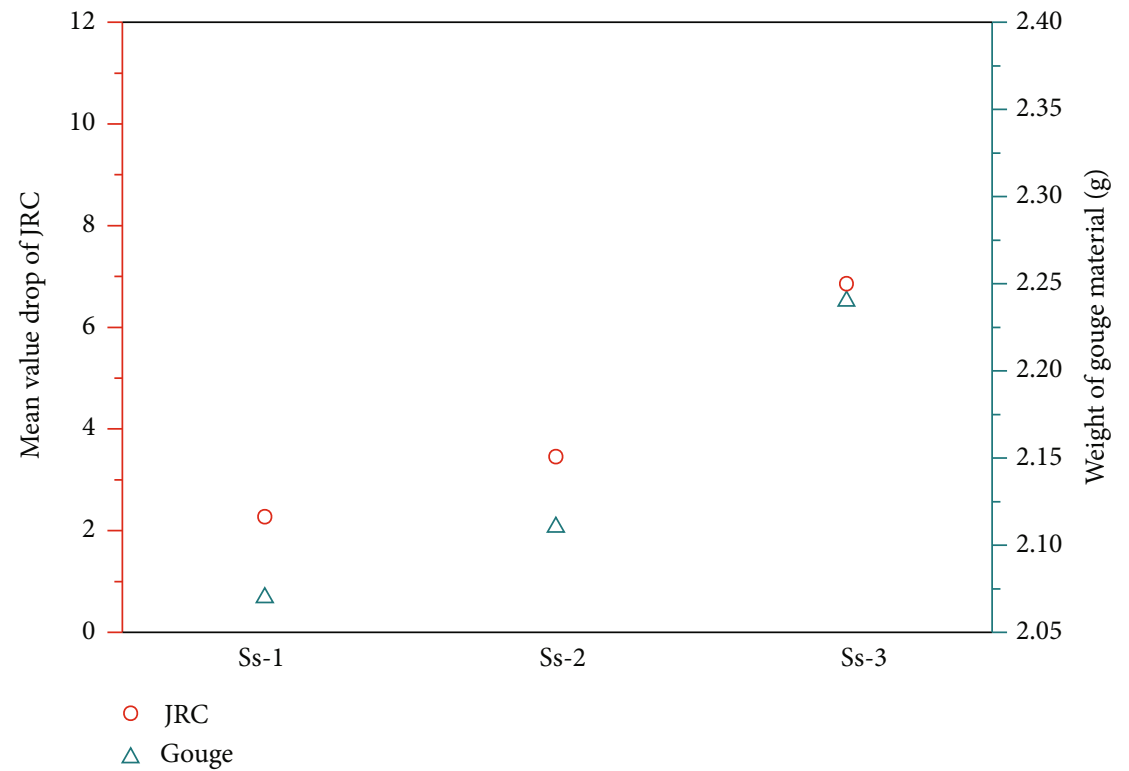

FIGURE 15: Mean value drop of JRC and weights of gouge material after testing under static stress.
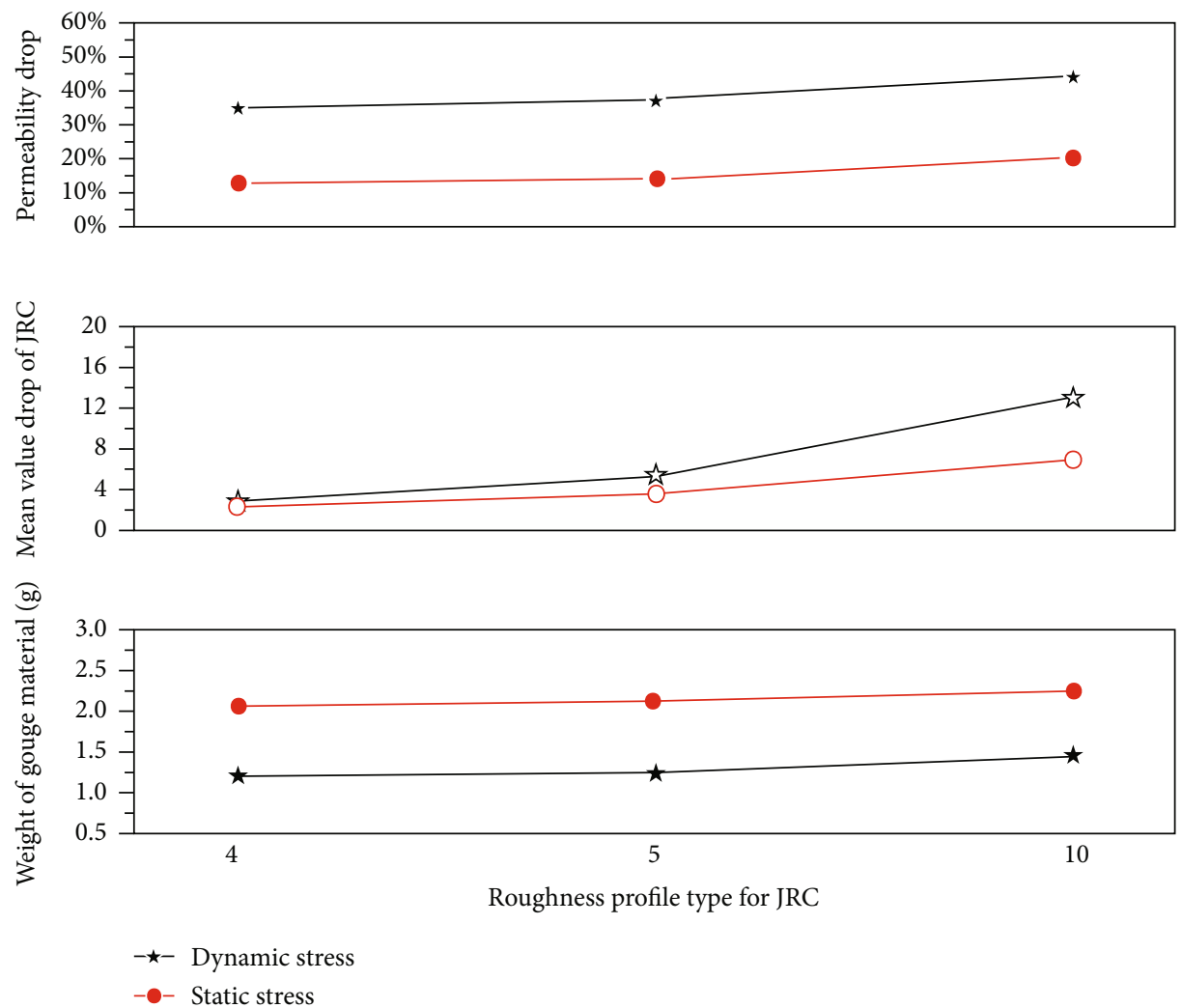

FIGURE 16: Comparing permeability drop, mean value drop of JRC, and weight of gouge material after testing under dynamic stress and static stress.

(2) The initial mean value drop of JRC of Sd-1 and Sd-2 is smaller than that of Sd-3 under dynamic stress, and the weights of fracture gouge produced of Sd-1 and Sd-2 are lower than those of Sd-3 during dynamic loading. This means that the larger roughness fracture surface leads to larger surface damage as indicated by more gouge production. The accumulation of gouge materials on larger roughness fracture surfaces causes slow drops of permeability 

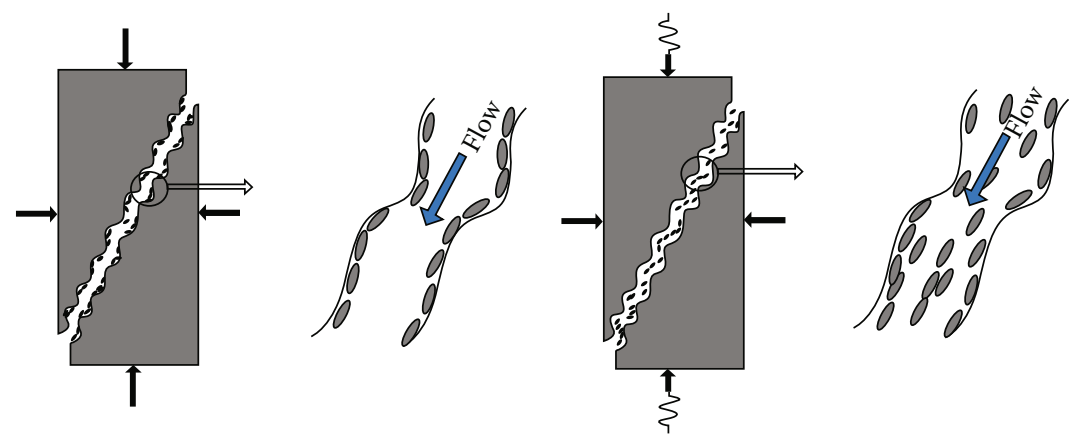

(a)

(b)



(c)

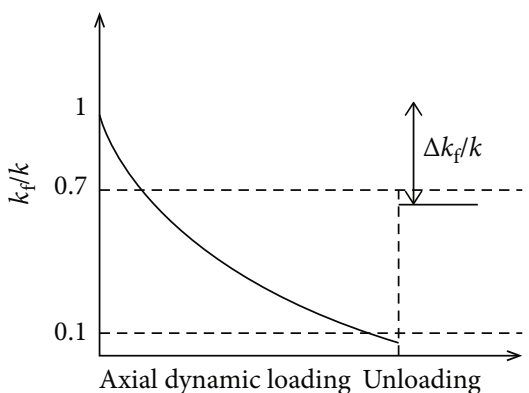

(d)

Figure 17: Permeability evolution modes of gouge material transport and flow mobilization. (a, b) Gouge material transport and flow mobilization under static stress and dynamic stress. (c, d) Permeability changes under static stress and dynamic stress.

(3) The permeability evolution modes considering gouge material transport and flow mobilization indicate that the gouge material transport and the flow mobilization tend to occur during dynamic stress. When the rough fracture surfaces are crushed under more intensive multiple dynamic impacts, the permeability drops of axial dynamic stress are larger than those of axial static stress. This interprets that the asperity degradations on fracture surface after testing under axial dynamic stress are larger than those under axial static stress. However, the weights of gouge materials on fracture surface after testing under axial dynamic stress are smaller than those under axial static stress

\section{Data Availability}

Data is included in the manuscript.

\section{Conflicts of Interest}

The authors declare that there is no conflict of interest regarding the publication of this paper.

\section{Acknowledgments}

This work was supported by the National Natural Science Foundation of China (41772313), Hunan Science and Technology Planning Project (No. 2019RS3001), and the Graduated Students' Research and Innovation Fund Project of Hunan Province (CX20190135 and 2019zzts079).

\section{References}

[1] M. Manga, I. Beresnev, E. E. Brodsky et al., "Changes in permeability caused by transient stresses: field observations, experiments, and mechanisms," Reviews of Geophysics, vol. 50, no. 2, 2012.

[2] Y. Liu, F. Dai, L. Dong, N. W. Xu, and P. Feng, "Experimental investigation on the fatigue mechanical properties of intermittently jointed rock models under cyclic uniaxial compression with different loading parameters," Rock Mechanics and Rock Engineering, vol. 51, no. 1, pp. 47-68, 2018.

[3] W. Wu, J. S. Reece, Y. Gensterblum, and M. D. Zoback, "Permeability evolution of slowly slipping faults in shale reservoirs," Geophysical Research Letters, vol. 44, no. 22, pp. 11,368-11,375, 2017.

[4] D. Vogler, F. Amann, P. Bayer, and D. Elsworth, "Permeability evolution in natural fractures subject to cyclic loading and gouge formation," Rock Mechanics and Rock Engineering, vol. 49, no. 9, pp. 3463-3479, 2016.

[5] K. Peng, Y. Q. Wang, Q. Le Zou, Z. P. Liu, and J. H. Mou, "Effect of crack angles on energy characteristics of sandstones under a complex stress path," Engineering Fracture Mechanics, vol. 218, article 106577, 11 pages, 2019.

[6] K. Peng, J. Zhou, Q. Zou, and F. Yan, "Deformation characteristics of sandstones during cyclic loading and unloading with varying lower limits of stress under different confining pressures," International Journal of Fatigue, vol. 127, pp. 82-100, 2019.

[7] K. Peng, J. Q. Zhou, Q. Le Zou, and X. Song, "Effect of loading frequency on the deformation behaviours of sandstones subjected to cyclic loads and its underlying mechanism," International Journal of Fatigue, vol. 131, article 105349, 2020. 
[8] V. M. Shmonov, V. M. Vitovtova, and A. V. Zharikov, "Experimental study of seismic oscillation effect on rock permeability under high temperature and pressure," International Journal of Rock Mechanics and Mining Sciences, vol. 36, no. 3, pp. 405-412, 1999.

[9] D. Ma, M. Rezania, H. S. Yu, and H. B. Bai, "Variations of hydraulic properties of granular sandstones during water inrush: effect of small particle migration," Engineering Geology, vol. 217, pp. 61-70, 2017.

[10] Z. L. Zhou, X. Cai, X. B. Li, W. Z. Cao, and X. M. Du, "Dynamic response and energy evolution of sandstone under coupled static-dynamic compression: insights from experimental study into deep rock engineering applications," Rock Mechanics and Rock Engineering, vol. 53, no. 3, pp. 13051331, 2020.

[11] X. Cai, Z. Zhou, and X. Du, "Water-induced variations in dynamic behavior and failure characteristics of sandstone subjected to simulated geo-stress," International Journal of Rock Mechanics and Mining Sciences, vol. 130, article 104339, 2020.

[12] W. G. Dang, H. Konietzky, L. F. Chang, and T. Frühwirt, "Velocity-frequency-amplitude-dependent frictional resistance of planar joints under dynamic normal load (DNL) conditions," Tunnelling and Underground Space Technology, vol. 79, pp. 27-34, 2018.

[13] W. G. Dang, H. Konietzky, T. Frühwirt, and M. Herbst, “Cyclic frictional responses of planar joints under cyclic normal load conditions: laboratory tests and numerical simulations," Rock Mechanics and Rock Engineering, vol. 53, no. 1, pp. 337-364, 2020.

[14] Z. Y. Song, H. Konietzky, and M. Herbst, "Bonded-particle model-based simulation of artificial rock subjected to cyclic loading," Acta Geotechnica, vol. 14, no. 4, pp. 955-971, 2019.

[15] D. Ma, H. Y. Duan, X. B. Li, Z. H. Li, Z. L. Zhou, and T. Bin Li, "Effects of seepage-induced erosion on nonlinear hydraulic properties of broken red sandstones," Tunnelling and Underground Space Technology, vol. 91, article 102993, 2019.

[16] D. Ma, J. Wang, X. Cai et al., "Effects of height/diameter ratio on failure and damage properties of granite under coupled bending and splitting deformation," Engineering Fracture Mechanics, vol. 220, article 106640,, p. 106640, 2019.

[17] D. Ma, J. J. Wang, and Z. H. Li, "Effect of particle erosion on mining-induced water inrush hazard of karst collapse pillar," Environmental Science and Pollution Research, vol. 26, no. 19, pp. 19719-19728, 2019.

[18] W. G. Dang, W. Wu, H. Konietzky, and J. Y. Qian, "Effect of shear-induced aperture evolution on fluid flow in rock fractures," Computers and Geotechnics, vol. 114, article 103152, 2019.

[19] Z. Y. Song, T. Frühwirt, and H. Konietzky, "Inhomogeneous mechanical behaviour of concrete subjected to monotonic and cyclic loading," International Journal of Fatigue, vol. 132, article 105383, 2020.

[20] M. D. Zoback and J. D. Byerlee, "Permeability and effective stress: geologic notes," AAPG Bulletin, vol. 59, pp. 154-158, 1976.

[21] K. Iwai, "Fundamental studies of fluid flow through a single fracture," International Journal of Rock Mechanics and Mining Sciences, PhD Thesis, University of California, Berkeley, 1976.

[22] Y. W. Tsang and P. A. Witherspoon, "Hydromechanical behavior of a deformable rock fracture subject to normal stress," Journal of Geophysical Research, vol. 86, no. B10, pp. 9287-9298, 1981.
[23] H. S. Lee and T. F. Cho, "Hydraulic characteristics of rough fractures in linear flow under normal and shear load," Rock Mechanics and Rock Engineering, vol. 35, no. 4, pp. 299-318, 2002.

[24] B. Li, Y. J. Jiang, T. Koyama, L. R. Jing, and Y. Tanabashi, "Experimental study of the hydro-mechanical behavior of rock joints using a parallel-plate model containing contact areas and artificial fractures," International Journal of Rock Mechanics and Mining Sciences, vol. 45, no. 3, pp. 362-375, 2008.

[25] Q. Yin, H. Jing, G. Ma, H. Su, and R. Liu, "Hydraulic properties of 3D rough-walled fractures during shearing: an experimental study," Journal of Hydrology, vol. 555, pp. 169-184, 2017.

[26] Q. Yin, H. Jing, G. Ma, H. Su, and R. Liu, "Investigating the roles of included angle and loading condition on the critical hydraulic gradient of real rock fracture networks," Rock Mechanics and Rock Engineering, vol. 51, no. 10, pp. 31673177, 2018.

[27] Y. L. Zhao, L. Y. Zhang, W. J. Wang, J. Z. Tang, H. Lin, and W. Wan, "Transient pulse test and morphological analysis of single rock fractures," International Journal of Rock Mechanics and Mining Sciences, vol. 91, pp. 139-154, 2017.

[28] Y. T. Wang, X. P. Zhou, and M. M. Kou, “An improved coupled thermo-mechanic bond-based peridynamic model for cracking behaviors in brittle solids subjected to thermal shocks," European Journal of Mechanics, A/Solids, vol. 73, pp. 282-305, 2019.

[29] S. Wang, X. Li, J. Yao et al., "Experimental investigation of rock breakage by a conical pick and its application to non-explosive mechanized mining in deep hard rock," International Journal of Rock Mechanics and Mining Sciences, vol. 122, article 104063, 2019.

[30] M. M. Kou, X. R. Liu, S. D. Tang, and Y. T. Wang, “3-D X-ray computed tomography on failure characteristics of rock-like materials under coupled hydro-mechanical loading," Theoretical and Applied Fracture Mechanics, vol. 104, article 102396, 2019.

[31] Z. Zhou, J. Zhang, X. Cai et al., "Permeability evolution of fractured rock subjected to cyclic axial load conditions," Geofluids, vol. 2020, Article ID 4342514, 12 pages, 2020.

[32] E. E. Brodsky, "A mechanism for sustained groundwater pressure changes induced by distant earthquakes," Journal of Geophysical Research, vol. 108, no. B8, pp. 1-10, 2003.

[33] J. E. Elkhoury, E. E. Brodsky, and D. C. Agnew, "Seismic waves increase permeability," Nature, vol. 441, no. 7097, pp. 11351138, 2006.

[34] L. Xue, H.-B. Li, E. E. Brodsky et al., "Continuous permeability measurements record healing inside the Wenchuan Earthquake Fault Zone," Science, vol. 340, no. 6140, pp. 15551559, 2013.

[35] Z. M. Shi and G. C. Wang, "Sustained groundwater level changes and permeability variation in a fault zone following the 12 May 2008, Mw7.9 Wenchuan earthquake," Hydrological Processes, vol. 29, no. 12, pp. 2659-2667, 2015.

[36] I. Faoro, D. Elsworth, and C. Marone, "Permeability evolution during dynamic stressing of dual permeability media," Journal of Geophysical Research: Solid Earth, vol. 117, no. 1, pp. 1-10, 2012.

[37] T. Candela, E. E. Brodsky, C. Marone, and D. Elsworth, "Laboratory evidence for particle mobilization as a mechanism for permeability enhancement via dynamic stressing," Earth and Planetary Science Letters, vol. 392, pp. 279-291, 2014. 
[38] R. Yan, G. C. Wang, and Z. M. Shi, "Sensitivity of hydraulic properties to dynamic strain within a fault damage zone," Journal of Hydrology, vol. 543, pp. 721-728, 2016.

[39] Z. Shi, S. Zhang, R. Yan, and G. Wang, "Fault zone permeability decrease following large earthquakes in a hydrothermal system," Geophysical Research Letters, vol. 45, no. 3, pp. 13871394, 2018.

[40] Y. Shi, X. Liao, D. Zhang, and C. P. Liu, "Seismic waves could decrease the permeability of the shallow crust," Geophysical Research Letters, vol. 46, no. 12, pp. 6371-6377, 2019.

[41] W. Q. Liu and M. Manga, "Changes in permeability caused by dynamic stresses in fractured sandstone," Geophysical Research Letters, vol. 36, no. 20, pp. 2-5, 2009.

[42] X. Cai, Z. Zhou, K. Liu, X. Du, and H. Zang, "water-weakening effects on the mechanical behavior of different rock types: phenomena and mechanisms," Applied Sciences, vol. 9, no. 20, p. 4450, 2019.

[43] N. Barton, "Review of a new shear-strength criterion for rock joints," Engineering Geology, vol. 7, no. 4, pp. 287-332, 1973.

[44] R. Tse and D. M. Cruden, "Estimating joint roughness coefficients," International Journal of Rock Mechanics and Mining Sciences, vol. 16, no. 5, pp. 303-307, 1979.

[45] N. Huang, R. C. Liu, and Y. J. Jiang, "Numerical study of the geometrical and hydraulic characteristics of 3D self- affine rough fractures during shear," Journal of Natural Gas Science and Engineering, vol. 45, pp. 127-142, 2017.

[46] Z. Ye and A. Ghassemi, "Injection-induced shear slip and permeability enhancement in granite fractures," Journal of Geophysical Research: Solid Earth, vol. 123, no. 10, pp. 90099032, 2018.

[47] W. F. Brace, J. B. Walsh, and W. T. Frangos, "Permeability of granite under high pressure," Journal of Geophysical Research, vol. 73, no. 6, pp. 2225-2236, 1968.

[48] H. C. Jang, J. Lee, and W. Lee, "Experimental apparatus and method to investigate permeability and porosity of shale matrix from Haenam Basin in Korea," Environmental Earth Sciences, vol. 74, no. 4, pp. 3333-3343, 2015.

[49] Y. Fang, D. Elsworth, C. Wang, T. Ishibashi, and J. P. Fitts, "Frictional stability-permeability relationships for fractures in shales," Journal of Geophysical Research, vol. 122, no. 3, pp. 1760-1776, 2017.

[50] H. Zhang, Z. Wan, Z. Feng, and J. Wu, "Shear-induced permeability evolution of sandstone fractures," Geofluids, vol. 2018, Article ID 2416481, 11 pages, 2018. 